\title{
Teaching effective collaborative information delivery and management
}

Conference or Workshop Item

Accepted Version

Nikolic, D. and Leicht, R. (2018) Teaching effective collaborative information delivery and management. In: 35th CIB W78 2018 Conference: IT in Design, Construction, and Management, October 1-3, 2018, Chicago, Illinois, United States, pp. 841-849. doi: https://doi.org/10.1007/978-3-03000220-6_101 Available at http://centaur.reading.ac.uk/79753/

It is advisable to refer to the publisher's version if you intend to cite from the work. See Guidance on citing.

Published version at: http://mypages.iit.edu/ cibw78/

To link to this article DOI: http://dx.doi.org/10.1007/978-3-030-00220-6_101

All outputs in CentAUR are protected by Intellectual Property Rights law, including copyright law. Copyright and IPR is retained by the creators or other copyright holders. Terms and conditions for use of this material are defined in the End User Agreement. 


\section{www.reading.ac.uk/centaur}

\section{CentAUR}

Central Archive at the University of Reading

Reading's research outputs online 


\title{
Teaching effective collaborative information delivery and management
}

\author{
Dragana Nikolic ${ }^{1}$ and Robert M. Leicht ${ }^{2}$ \\ ${ }^{1}$ University of Reading, School of the Built Environment, Whiteknights, Reading RG6 6AG, \\ UK; PH +44 0118 3726039; email: d.nikolic@reading.ac.uk \\ ${ }^{2}$ The Pennsylvania State University, Department of Architectural Engineering, University \\ Park, 16802 PA, US; PH +1 814 8632080; rmleicht@engr.psu.edu
}

\begin{abstract}
This paper explores a pedagogical approach to teaching construction students how to plan, execute and monitor an efficient collaborative information delivery plan from the perspective of managing scope of work, time, resources and communication. This study extends the work of similar studies that tasked students with developing BIM process maps to gauge any shift in the students' perception on their ability to map the process. In this context, students in the final year of an undergraduate construction management program participate in a team-based project to plan, execute, update and evaluate the efficiency of their collaborative information delivery plan. To plan this process, the students use references including both UK-based BIM Level 2 standards and US-based CIC BIM Project Execution Planning Guide. Through a semester-long sequence of modeling and planning activities, the students specifically aim to address the following learning objectives: (i) define and allocate project- and information delivery responsibilities; (ii) identify information workflows and respective tasks with estimated durations, and (iii) execute and update their plan to record actual tasks, durations and outcomes. Comparing the initial and executed plan would provide the students with the basis to reflect on the influence of formal planning guides on their understanding of efficient collaborative information management and delivery. In this aspect, the study contributes to the knowledge of how to pedagogically deploy industry-oriented process planning approaches for effectively teaching roles and responsibilities for engaging in interdisciplinary teams.
\end{abstract}

Keywords: problem-based learning, BIM, collaborative process, management.

\section{Introduction}

The construction industry in the UK, as well as globally, is currently pressed to improve the efficiency of project delivery and generate value with a recent shift in emphasis on the structured data set at every project stage. The design and construction industry in the UK tendering for publicly procured work is currently faced with a government mandate to deliver projects compliant with building information modeling (BIM) standards, methods and protocols, published as a number of BIM docu- 
ments. Furthermore, the goal of the UK mandate and other similar global developments is to reduce the effects of uncertainty and offer guidance to increase the accuracy, completeness and usability of the generated information down the activity stream. In terms of teaching students how this mandate translates in practice, the challenge is the reality that these published standards and processes have been slow to adopt among other due to an overwhelming need to up-skill the existing workforce in how to properly apply them on the projects. This in turn presents educators with the challenge to adequately prepare the graduates with relevant knowledge and collaborative, problem-solving and teamwork skills $[1,2]$.

Though construction engineering and management students tend to master software-related skills, strong communication and teamwork skills have been deemed essential to apply knowledge in practice [3-5]. At the same time, the increase in project complexity necessitates more efficient construction processes and cost-effective management of available resources. Thus, the students are expected to develop skills to leverage their technical knowledge as part of an integrated design and construction team beyond the simple capability to use the software. It is this knowledge and epistemological development in students that is significantly more challenging to embed and assess using traditional approaches. To address some of the challenges, a growing body of research suggests that providing students with an experiential learning environment advances problem-solving and decision-making skills. The development and adoption of BIM can be viewed as an opportunity to engage students in more practicable problems and projects that allow the development and assessment of the integrated process design skills that are much needed.

\section{Background}

\subsection{Approaches to BIM process planning}

Broad body of literature discusses a range of building information modeling and management (BIM) aspects seen to offer solutions to ailing inefficiencies in how information is authored, shared and used in design, construction and operations. A series of UK government funded reports produced between the 1970s and late 1990s (e.g. [6-8]) gave way to the government strategy [9], that defined BIM maturity levels with the mandate to use BIM (level 2) on all publicly procured projects starting in April 2016. Though there is much debate on the reality of its implementation [10], the mandate involves a number of required and voluntary measures in an effort to decrease industry fragmentation through a more structured approach to information exchange and project management. What BIM Level 2 in essence mandates is a file-based collaboration and library management within a centrally coordinated data environment.

In this context, the implications for teaching BIM are found in a gradual shift from an emphasis on the digital model as a source of knowledge [11] towards "value creating collaboration" [12] and "collaborative way of working, underpinned by the digital technologies" [13]. While the claimed benefits of BIM approaches span across disciplines and scopes of implementation, from a collaboration standpoint, BIM is still 
regarded as a facilitator of concurrent rather than sequential information workflows and more integrated tasks through a shared (3D) model [14]. This approach in turn, requires careful planning of information management and team coordination activities, typically documented in what is known as a BIM execution plan (also BEP). BIM execution plan documents client and stakeholders' goals and requirements for the project, as well as standards, methods and procedures the teams adhere to for authoring, sharing, coordinating and delivering requested information. In the UK a set of formal standards such as BS1192:2007 and specifications such as PAS1192 series prescribe the methods for structuring the common data environment (CDE). The purpose of the $\mathrm{CDE}$ as a single source of information and the file naming convention is to prevent mistakes from duplication, incorrect file versioning, or use of information for purposes other than indicated. Through explicit file and task management strategies the intent is to encourage the conversation among the team members early and continuously throughout the project.

In the US similar objectives through a slightly different approach have been addressed in the BIM Project Execution Planning guide [15], which offers a structured procedure for planning the collaborative process and communication on a project. The guide has already been implemented in teaching undergraduate and postgraduate students process-mapping activities and inter-disciplinary collaboration [16-18]. Still, approaches to teaching BIM remain as diverse as the topic itself. While a large number of studies have explored the necessary skills relative to the new computing tools as well as the dynamics of sharing files and collaborating, there has been little work to explore how learning related to integrated processes can best engage the students to advance their metacognitive and epistemological development.

\subsection{Pedagogy around teaching BIM-enabled collaboration}

The ability to identify a problem, evaluate options and make decisions in a collaborative setting are all necessary skills for students in the construction and architectural engineering disciplines. The design and construction fields are dynamic and dominated by complex, ill-defined problems with many possible solutions. Planning a collaborative project delivery in a BIM context is a complex and interdependent process that typically includes a number of considerations such as the project context, scope, goals, information requirements, information exchanges, needed and available resources, technologies and other contingencies for delivering the requested information on time. Planning how to do this process efficiently, as the BIM mandate implies, leaves little room for oversight and plenty of managerial issues for students lacking professional experience to absorb and apply. Studies have been tackling these types of pedagogical challenges by considering questions of soft skills such as leadership, interdependence, social communication and teamwork skills in both collocated and remote settings $[19,20]$ as well as supporting information technology needs.

At the same time, rapid developments in BIM technologies and shifting focus in the BIM discourse have broadened the scope for educators to effectively tackle what needs to taught, when or how $[14,21]$. However, the growing consensus to move beyond teaching technology decoupled from the practical interdisciplinary and col- 
laborative context emphasizes the need for self-directed learning and epistemological development in problem-based settings. Epistemological development, or epistemic cognition, relates to the ability to understand the nature of the problem and deciding what types of problem-solving strategies are appropriate [22]. This level of cognition builds upon the abilities associated with performing a task, and metacognition, which allows one to choose among cognitive strategies. Perry [23] describes this as a way a person makes sense of knowledge as they are challenged with meaning in both philosophical and technical areas. As Salner [24] points out in her framing of systems thinking in epistemological development, few students move from multiplicity to contextual relativism. Salner further asserts that this development is associated with placing students in a position or environment that pressures them to generate their own syntheses and reflect upon their own cognitive patterns. This type of 'pressure' aligns with the common employment of project-based learning in construction management curricula.

\section{Method: Course overview and objectives}

Current employability rates of our graduates from the School of Construction Management and Engineering are in the upper ninetieth percentiles ${ }^{1}$ and this reflects the School's ongoing strategy to identify and equip students with employable and necessary skills while working closely with industry. Collaboration and communication skills are those always raised as worth improving and strengthening, which has incited current discussions about introducing project-based work as early as in the first year.

To illustrate some of these pedagogical challenges, the authors describe their experience from a senior level undergraduate construction management and engineering elective course that introduces students to advanced concepts and topics on how digital technologies affect collaborative practices. The course applies the techniques of self-directed, research-driven and reflective learning experience through a problembased group project and a series of small practical assignments where students learn new software through online tutorials. Specifically, the goal of the module is to raise practical questions of how to work and collaborate with different disciplines when technology, information formats, exchanges and management issues start to bring tension into this practice. The course enrolled 25 students with background in quantity surveying, construction management, building surveying and mechanical engineering. The lecture-based approach caused challenges in the past when guest lecturers from industry and academia revealed often conflicting views of the existing practices and concept definitions. For students who are accustomed to well-structured problems, this can become challenging if there is no understanding of the reasons for differing views. Thus, specific learning objectives in the module were for the students to: 1) identify goals, tasks and methods for effective collaboration using existing guidelines, standards and specifications; 2) build collaborative and communication skills through student-to-student interactions for negotiating and allocating roles, responsibilities

$1 \quad$ https://www.reading.ac.uk/ready-to-study/study/subject-area/surveying-and-constructionug/bsc-construction-management-and-surveying.aspx 
and milestones; 3 ) identify and use technologies deemed appropriate for respective tasks; and 4) evaluate and reflect on the applied strategies and team performance to draw relevant lessons about usability of BIM approaches and their understanding of effective collaboration needs.

Educational research in engineering reports that ill-defined problems can be effectively addressed through project-based or problem-based work [25]. Project-based or problem-based learning, are both similar in that they present students with an openended or a "messy" real-world problem with no singular solution and which they try to solve by working in small groups, and subsequently reflecting on their experience $[26,27]$. The project assignment asked student teams to deliver specific project information (well-defined product) by following their own developed BIM-compliant collaboration practice (ill-defined process) to manage time, tasks, roles and resources.

Setting the scene. The students self-enrolled into 6 teams which were introduced to the semester-long course project. The project asked the students to plan, execute and evaluate their collaborative approach to producing a structured set of completed hospital design project information. The teams received the initial set of exchange files in IFC and Revit format, which included architectural, structural, mechanical, plumbing, electrical, fire and sprinkler system models of a large hospital project, with one floor wing remaining to be completed. In order to get the students started planning their collaborative approach, the first three weeks introduced students to the UK and international BIM initiatives, published documents, standards and protocols. The first step for the student teams was to understand the goal of the mandate - eliminate waste and create near zero-defect information. The second part of the problem was challenging how to actually plan this process, apply these documents and standards in a project, and how will the process work? Both the industry and students face the same challenge of delivering a project using a large number of published documents that predominantly outline what needs to be done, but not necessarily how. The complexity of this problem is that there is no single solution. Thus, students were expected to establish goals, review published documentation, prioritize it, understand tradeoffs, and negotiate the approach with other team members, ultimately documenting decisions in their BIM plan to produce a coordinated set of project information. Thus, solving the problem had to engage student teams in planning and executing the work by searching for resources, discussing the problem, allocating responsibilities and addressing any questions with the instructors through two planned "client-team" meetings. The teams were also given a general timeline for agreeing on the project roles and responsibilities; familiarizing with the project information and its quality through initial clash detection; producing initial and updated plans to consult with the client, and final delivery.

How students work. Planning for group work is always challenging due to known issues of possible uneven workload or otherwise specific group dynamics. Drawing upon previous research into group work [28-30] several strategies were employed as an attempt to improve the group experience. These included: 1) an option for students 
to self-select given that in their final year they have fair knowledge of each other and thus can choose team members based on mutual expectations, work ethics and performance goals; 2) suggest project roles to help plan the workload, but let the students negotiate the division of work and responsibilities based on their skills and other commitments as a way to exercise communication and negotiation skills; 3) have planned progress check meetings with each group and act as a mediator and facilitator, and lastly, 4) use peer-evaluation to alleviate any discontent with members who do not contribute. The first meeting with the teams took place in week 4 to discuss their initial plan and address any questions, followed by the second progress meeting in week 8 to discuss their updated plan. During the progress check meetings, an informal survey was distributed to all teams asking each team member to, among other state their level of confidence in understanding the type and amount of work required to do, as well as their ability to do the work and deliver it on time. This revealed a range of instances where some members did not read the assignment, or understood it differently, or had varying sense of ability to do it at that stage. As a result, in addition to the instructors' feedback and steering, the set of questions prompted internal discussion among the team members. Still, at this stage the prevalent questions were quite general, indicating confusion and frustration over not knowing where to start and focused on clarifying the expectations of the assignment, as they seemed uncomfortable with the perceived latitude offered in how they approach it. Ultimately, while groups were tutored in the same way, there was a possibility that some groups moved in a different direction, but reaching equally informative results and conclusions. This became evident in week 8 , in the second progress check meeting, where teams began to discuss specific approaches to how they were implementing the collaborative process. The instructors primarily raised reflective questions (e.g. "Why did you decide to do it that way?", "What information did you use in the process?" or "How did you agree on this procedure?"). In this manner, the objective was to help students arrive to answers by articulating the decisions they may have made as they were running into numerous practical problems (e.g. what file-sharing platform they need to exchange files, how to reference each other files without duplicating, or who is responsible for the file checking) and why they deemed certain options more viable than others.

Assessing the learning. Project-based learning emphasizes self-directed learning supported by small group work [27]. The group work helps each of the team members to contribute in gathering information and discuss questions. The assessment in this course was structured around the collaborative considerations documented in the final BIM strategy report the teams presented at the last day of class, along with lessons learned subsequently captured in the individual reflective reports as a critical component of the learning experience. The group report structure and formatting was open to team's decision and the extent to which they considered existing guidelines and templates. Still, the report had to include the record of initial and any subsequently updated plans with tasks, milestones, deadlines, and responsible parties as a minimum. The goal was to capture the evolution in the team's approach to delivering the project and any change in the team's definition of work scope and internal project targets. 
Though formative feedback to stimulate team reflection has been integral part of the process throughout the term, the individual reflective report following the group work intended to help students articulate their collaborative experience and knowledge gained through identifying problems, discussing options, managing their own and other member's input in exploring solutions and delivering information. The primary goal of a written reflective report is to encourage the transfer of learning to the workplace by analyzing and reflecting on the decisions made during the group work, evaluation of how well they worked and what they would do differently next time in the form of broader recommendations. This metacognitive approach is an extension of the guided reflection in experiential learning concepts [31, 32].

\section{$4 \quad$ Findings and lessons learned}

Students' confusion about the project deliverables and scope of work marked the initial stages of the group work, though towards the end, all teams met the learning objectives to (i) define and allocate project- and information delivery responsibilities; (ii) identify information workflows and respective tasks with estimated durations, and (iii) execute and update their plan to record actual tasks, durations and outcomes. The quality of the final group BIM plans was consistent, though the reflective accounts gave a wide range of valuable insights into the learning and decision making process, and the way students considered addressing the challenges should they repeat the process (Table 1).

Table 1. Students' reflection: considerations for effective collaboration.

\begin{tabular}{lll}
\hline Skills needed & Improvement strategies & Challenges \\
\hline Time management & Team's workloads and schedule & Guidelines complexity \\
Accountability & Meeting strategy & Technology issues \\
Positive attitude & Adequate task allocation & Logistics \\
Commitment & Task prioritization & Enforcing team deadlines \\
Technical confidence & Task time estimates & \\
Knowing own strengths & Time allocation for brainstorming & \\
\hline
\end{tabular}

All teams initially defined discipline-specific roles based on systems knowledge, software skills and interests within the team. There was a learning curve until the teams understood their individual members' skill levels before they began adjusting their model management. The initial plans showed tasks and roles that were mostly focused on model authoring, and general milestones broadly set to durations in weeks rather than deliverable or handover dates. It was a common point of discussion amongst teams in meetings that the roles and responsibilities often appeared vaguely defined. For example, the responsibilities for managing information sharing were quite different where one group created a role specifically for this purpose, while another group identified this as a key area that no one was managing, but only after missing a deadline. Responsibilities for doing the clash detection, setting up the 
common data environment, coordinating the team file exchanges and scheduling meetings were gradually recognized as the work progressed, after the discussions with the instructors and consulting the BIM standards and guidelines.

Students also applied and adapted existing standards and guidelines in different ways, often creating a hybrid. They noted the straightforwardness of the US BIMex approach to defining goals, uses and priorities, while the UK's BS1192 and PAS1192 offered more specific guidelines for managing file exchanges through CDE and file naming. Some groups used a process modeling approach, others used Gantt charts to plan and communicate the process and handoffs, while others used tables that documented deliverables and deadlines. File naming structure though recognized as part of the mandate was inconsistently applied - some groups had an agreed file naming convention, but did not use it, while other groups started without one, but quickly realized the need for it when the number of files started to increase rapidly.

Students generally appreciated the unexpected nature of the project that required skills to manage time that was often underestimated ("Time estimates were based on meeting the deadline, rather than actual amount of time needed to successfully carry them out") or work scope that was unaccounted for. None of the teams considered the time and skills needed to produce IFC and COBie files even though they had no experience with either, which resulted in files that were missing data or misaligned. Management challenges were raised in the lack of specifically assigned responsibilities, which caused quality problems: "Updating the BEP, like many other tasks, was open to everybody, whoever had the chance to do so. Hence its mediocrity." Communicating and monitoring the team members' work progress and lag resolution tended to be loosely structured, missing, or otherwise challenging. Some of the teams experienced consistent delays because members were not sharing work by their internally set deadlines, but also did not communicate the reasons for delays and there were no mitigation strategies put in place. It was observed that developing and agreeing to a plan did not necessarily guarantee adhering to it. The necessity to hold members accountable, motivated and engaged were identified as considerations for effective collaboration. Other students raised the need to more carefully consider each other's skills, workloads and schedules and have more strategic, rather than ad hoc meetings to properly tackle problems that were deemed complex.

\section{Conclusions}

Overall, some of the students welcomed the opportunity to tackle the problem type this course project presented, which was also viewed as different from other projects they typically do. The expectation to master additional software skills become secondary to tangible challenges in managing expectations and work ethics among team members towards effective collaboration. The overall experience of this year's module is that it has in part successfully introduced and reinforced the iterative and complex nature of the collaborative process planning and management. Initial and updated plans demonstrated a gradual increase in task considerations and timelines, though still leaving much room for added clarity and detail. At the same time, the limited 
time of one term and the learning curve to internalize, apply and evaluate BIM strategies poses challenges to effectively balance multifaceted nature of the collaborative project delivery. The course project focused on supporting and evaluating the learning process where students' understanding of the possible reasons for the given outcomes is more informative than the final product. This problem-based approach carries broader implications to similar initiatives around teaching collaborative BIM. The process demonstrated the value and the need for formative feedback and careful coaching on the productive team discussions. Working with student groups is timeintensive and thus effective for smaller enrollment, but the reality of larger classes will necessitate adequate approaches to problem-based learning. The assessment of problem-based learning warrants further investigation into more creative methods to both scaffold and assess the learning process. This suggests focusing specifically on skills usually not part of a standard assessment, such as communication, work planning and collaborative team-work skills.

\section{References}

1. Koutsabasis, P., Vosinakis, S., Malisova, K., Paparounas, N.: On the value of Virtual Worlds for collaborative design. Design Studies. 33, 357-390 (2012). doi:10.1016/j.destud.2011.11.004

2. Kronholm, M.M.: The impact of developmental instruction on reflective judgement. Review of Higher Education. 19, 199-225 (1996)

3. Fruchter, R.: Dimensions of teamwork education. International Journal of Engineering Education. 17, 426-430 (2001)

4. Kalay, Y.E.: Enhancing multi-disciplinary collaboration through semantically rich representation. Automation in Construction. 10, 741-755 (2001). doi:10.1016/S09265805(00)00091-1

5. O’Brien, W., Soibelman, L., Elvin, G.: Collaborative design processes: an active-and reflective-learning course in multidisciplinary collaboration. Journal of Construction Education. 8, 78-93 (2003)

6. Crawshaw, D.T.: Coordinating working drawings. , Building Research Establishment, Current Paper CP 60/76, Watford, UK (1976)

7. Latham, S.M.: Constructing the team. (1994)

8. Egan, J.: Rethinking construction. Department of the Environment, Transport and the Regions, London (1998)

9. Cabinet Office: Government Construction Strategy. Cabinet-Office London (2011)

10. Dainty, A., Leiringer, R., Fernie, S., Harty, C.: Don't believe the (BIM) hype: the unexpected corollaries of the UK'BIM revolution'. In: Engineering Project Organizations Conference. , The University of Edinburgh, Scotland, UK (2015)

11. National Institute of Building Sciences: National Building Information Model (BIM) Standard- United States, http://www.buildingsmartalliance.org/index.php/nbims/, (2008)

12. U.K. BIM taskgroup: U.K. BIM taskgroup. , http://www.bimtaskgroup.org (2014)

13. HMGovernment: Industrial strategy: government and industry in partnership. www.bis.gov.uk. 22 (2012)

14. Becerik-Gerber, B., Ku, K., Jazizadeh, F.: BIM-Enabled Virtual and Collaborative Construction Engineering and Management. Journal of Professional Issues in Engineering Education and Practice. 138, 234-245 (2012). doi:10.1061/(ASCE)EI.1943-5541.0000098 
15. Computer Integrated Construction Research Program: BIM Project Execution Planning Guide - Version 2.1. The Pennsylvania State University, University Park, PA, USA (2011)

16. Poerschke, U., Holland, R., Messner, J., Pihlak, M.: BIM Collaboration Across Six Disciplines. In: Proceedings of the International Conference on Computing in Civil and Building Engineering 2010. p. 6 pages. , Nottingham, UK (2010)

17. Holland, R., Messner, J., Parfitt, K., Poerschke, U., Pihlak, M., Solnosky, R.: Integrated Design Courses Using BIM as the Technology Platform. In: Education Thread. p. 12 Pages. , Washington, DC, USA (2010)

18. Ayer, S.K., Cribbs, J., Hailer, J.D., Chasey, A.D.: Best Practices and lessons learned in BIM Project Execution Planning in Construction Education. In: Proceedings of 9th BIM Academic Symposium and Job Task Analysis Review, Washington, DC. pp. 167-174 (2015)

19. Sancho-Thomas, P., Fuentes-Fernández, R., Fernández-Manjón, B.: Learning teamwork skills in university programming courses. Computers \& Education. 53, 517-531 (2009). doi:10.1016/j.compedu.2009.03.010

20. Fruchter, R.: Innovation in engaging learning and global teamwork experiences. In: Information Technology 2003. pp. 1-13. , Nashville, Tennessee, USA (2003)

21. Sacks, R., Pikas, E.: Building Information Modeling Education for Construction Engineering and Management. I: Industry Requirements, State of the Art, and Gap Analysis. Journal of Construction Engineering and Management. 139, 04013016 (2013). doi:10.1061/(ASCE)CO.1943-7862.0000759

22. Kitchner, K.S.: Cognition, Metacognition, and Epistemic Cognition. HDE. 26, 222-232 (1983). doi:10.1159/000272885

23. Perry, W.G.: Forms of Intellectual and Ethical Development in the College Years: A Scheme. Jossey-Bass Higher and Adult Education Series. Jossey-Bass Publishers, 350 Sansome St (1999)

24. Salner, M.: Adult cognitive and epistemological development in systems education. Systems Research. 3, 225-232 (2011). doi:10.1002/sres.3850030406

25. Perrenet, J.C., Bouhuijs, P.A.J., Smits, J.G.M.M.: The Suitability of Problem-based Learning for Engineering Education: Theory and practice. Teaching in Higher Education. 5, 345-358 (2000). doi:10.1080/713699144

26. Hmelo-Silver, C.E.: Problem-Based Learning: What and How Do Students Learn? Educational Psychology Review. 16, 235-266 (2004). doi:10.1023/B:EDPR.0000034022.16470.f3

27. Walker, A., Leary, H., Hmelo-Silver, C.E.: Essential readings in problem-based learning. Purdue University Press, West Lafayette, Indiana, USA (2015)

28. Boud, D., Cohen, R., Sampson, J.: Peer Learning and Assessment. Assessment \& Evaluation in Higher Education. 24, 413-426 (1999). doi:10.1080/0260293990240405

29. Dochy, F., Segers, M., Sluijsmans, D.: The use of self-, peer and co-assessment in higher education: A review. Studies in Higher Education. 24, 331-350 (1999). doi:10.1080/03075079912331379935

30. Kriflik, L., Mullan, J.: Strategies to Improve Student Reaction to Group Work. Journal of University Teaching and Learning Practice. 4, 13-27 (2007)

31. Schön, D.A.: Educating the reflective practitioner: Toward a new design for teaching and learning in the professions. Australian Journal of Adult Learning. 50, 448-451 (2010)

32. Rosier, G.: Using reflective reports to improve the case method. Journal of Mgmt Development. 21, 589-597 (2002). doi:10.1108/02621710210437563 